University of Nebraska - Lincoln

DigitalCommons@University of Nebraska - Lincoln

USGS Staff -- Published Research

US Geological Survey

2014

Development of a generic auto-calibration package for regional ecological modeling and application in the Central Plains of the United States

Yuping $\mathrm{Wu}$

U.S. Geological Survey (USGS) Earth Resources Observation and Science (EROS) Center, rocky.ypwu@gmail.com

Shuguang Liu

U.S. Geological Survey (USGS) Earth Resources Observation and Science (EROS) Center, South Dakota State University, sliu@usgs.gov

Zhengpeng Li

University of Maryland, ESSIC

Devendra Dahal

Stinger Ghaffarian Technologies, USGS EROS Center

Claudia Young

ERT Inc., USGS EROS Center

See next page for additional authors

Follow this and additional works at: http://digitalcommons.unl.edu/usgsstaffpub

Wu, Yuping; Liu, Shuguang; Li, Zhengpeng; Dahal, Devendra; Young, Claudia; Schmidt, Gail; Liu, Jinxun; Davis, Brian; Sohl, Terry; Werner, Jeremy; and Oeding, Jennifer, "Development of a generic auto-calibration package for regional ecological modeling and application in the Central Plains of the United States" (2014). USGS Staff -- Published Research. 845.

http://digitalcommons.unl.edu/usgsstaffpub/845

This Article is brought to you for free and open access by the US Geological Survey at DigitalCommons@University of Nebraska - Lincoln. It has been accepted for inclusion in USGS Staff -- Published Research by an authorized administrator of DigitalCommons@University of Nebraska - Lincoln. 
Authors

Yuping Wu, Shuguang Liu, Zhengpeng Li, Devendra Dahal, Claudia Young, Gail Schmidt, Jinxun Liu, Brian Davis, Terry Sohl, Jeremy Werner, and Jennifer Oeding 


\title{
Development of a generic auto-calibration package for regional ecological modeling and application in the Central Plains of the United States
}

\author{
Yiping $\mathrm{Wu}^{\mathrm{a}, *}$, Shuguang Liu ${ }^{\mathrm{b}, \mathrm{c}, *}$, Zhengpeng $\mathrm{Li}^{\mathrm{d}}{ }^{\mathrm{d}}$, Devendra Dahal ${ }^{\mathrm{e}}$, Claudia J. Young ${ }^{\mathrm{f}}$, Gail L. Schmidt ${ }^{\mathrm{e}}$, \\ Jinxun Liu ${ }^{\mathrm{e}}$, Brian Davis ${ }^{\mathrm{e}}$, Terry L. Sohl ${ }^{\mathrm{b}}$, Jeremy M. Werner ${ }^{\mathrm{b}}$, Jennifer Oeding ${ }^{\mathrm{e}}$ \\ a ASRC Research and Technology Solutions, U.S. Geological Survey (USGS) Earth Resources Observation and Science (EROS) Center, Sioux Falls, SD 57198, USA \\ ${ }^{\mathrm{b}}$ U.S. Geological Survey (USGS) Earth Resources Observation and Science (EROS) Center, Sioux Falls, SD 57198, USA \\ c Geographic Information Science Center of Excellence, South Dakota State University, Brookings, SD 57007, USA \\ d Earth System Science Interdisciplinary Center (ESSIC), University of Maryland, College Park, MD 20740, USA \\ e Stinger Ghaffarian Technologies, USGS EROS Center, Sioux Falls, SD 57198, USA \\ ${ }^{\mathrm{f}}$ ERT Inc., USGS EROS Center, Sioux Falls, SD 57198, USA
}

\section{A R T I C L E I N F O}

\section{Article history:}

Received 19 September 2013

Received in revised form 15 November 2013

Accepted 20 November 2013

Available online 28 November 2013

\section{Keywords:}

Biogeochemical modeling

FME

Parameter optimization

$\mathrm{R}$

Remote sensing

SCE

\begin{abstract}
A B S T R A C T
Process-oriented ecological models are frequently used for predicting potential impacts of global changes such as climate and land-cover changes, which can be useful for policy making. It is critical but challenging to automatically derive optimal parameter values at different scales, especially at regional scale, and validate the model performance. In this study, we developed an automatic calibration (auto-calibration) function for a well-established biogeochemical model-the General Ensemble Biogeochemical Modeling System (GEMS)-Erosion Deposition Carbon Model (EDCM)-using data assimilation technique: the Shuffled Complex Evolution algorithm and a model-inversion R package-Flexible Modeling Environment (FME). The new functionality can support multiparameter and multi-objective auto-calibration of EDCM at the both pixel and regional levels. We also developed a post-processing procedure for GEMS to provide options to save the pixel-based or aggregated county-land cover specific parameter values for subsequent simulations. In our case study, we successfully applied the updated model (EDCM-Auto) for a single crop pixel with a corn-wheat rotation and a large ecological region (Level II)-Central USA Plains. The evaluation results indicate that EDCM-Auto is applicable at multiple scales and is capable to handle land cover changes (e.g., crop rotations). The model also performs well in capturing the spatial pattern of grain yield production for crops and net primary production (NPP) for other ecosystems across the region, which is a good example for implementing calibration and validation of ecological models with readily available survey data (grain yield) and remote sensing data (NPP) at regional and national levels. The developed platform for auto-calibration can be readily expanded to incorporate other model inversion algorithms and potential $\mathrm{R}$ packages, and also be applied to other ecological models.
\end{abstract}

Published by Elsevier B.V.

\section{Introduction}

Mathematical models, especially process-oriented models, are widely used to support decision making in environmental disciplines because they can characterize and predict landscape processes and consequences (Liu et al., 2008b). The majority of ecological models are built for research purposes, but increasingly also for forecasting and management purposes (Marta-Almeida et al., 2012; Rykiel, 1996). These numerical models, however, usually contain parameters which may be hard to measure (Janssen and Heuberger, 1995; Luo et al., 2001;

\footnotetext{
* Corresponding authors.

E-mail addresses: ywu@usgs.gov, rocky.ypwu@gmail.com (Y.Wu), sliu@usgs.gov (S. Liu).
}

Van Oijen et al., 2005; Wu and Liu, 2012a; Yuan et al., 2012) or cannot be determined using field measurement because of scaling effects (discrepancies between measurement and modeling scales) (Beven, 2001; Juston et al., 2010). Hence, model calibration is required to estimate and adjust model parameters and constants to improve the agreement between simulations and the corresponding observations (Janssen and Heuberger, 1995; Larssen et al., 2007; Pereira et al., 2008; Rykiel, 1996; Zhang et al., 2009a). This procedure is fundamental and critical for ecological model applications (Janssen and Heuberger, 1995; Larssen et al., 2007; Mazzotti and Vinci, 2010; Rykiel, 1996).

Conventional manual calibration can incorporate the knowledge and experience of modelers through analysis of results and common sense reasoning when searching new values for each parameter (Pereira et al., 2008). However, it is subjective, time-consuming, and 
challenging when calibrating more than one parameter and satisfying multiple constraints (i.e., multi-objective calibration) for biogeochemical models (Liu et al., 2008b). Further, it could be impractical to obtain the globally optimal set of parameter values for non-linear models using a manual approach which is labor intensive and associated with subjective experience. Additionally, the size of a study area can dramatically increase the difficulty to derive spatially-explicit parameter values (i.e., the spatial variability of a parameter) (Liu et al., 2008b).

With the development of computer technology, auto-calibration was proposed and attracted increasing attention over the past decades (Gupta et al., 1999; Vrugt et al., 2003; Zhang et al., 2009b). Simple techniques such as controlled random search or linear regression methods can be useful for some simple data-oriented models. However, because these techniques are based on systematic and exhaustive generation of parameter arrays and thus require a huge number of model iterations, they are inapplicable of deriving the globally optimal values for nonlinear, process-oriented models which are usually computationallyintensive. From literature, there are a number of global optimization techniques available, such as Shuffled Complex Evolution (SCE) (Duan et al., 1992), Artificial Neural Network (ANN), Genetic Algorithm (GA) (Goldberg, 1989; Holland, 1975), Multi-objective Evolutionary Algorithm (MOEA), Kalman Filter, and the Flexible Modeling Environment (FME) (Soetaert and Petzoldt, 2010), which was developed and implemented using the General Public License (GPL) R software (R Development Core Team, 2009). For example, Wu and Liu (2012a) developed a universal modeling framework to incorporate the R-based FME into a Fortranbased model such as the Soil and Water Assessment Tool (R-SWATFME) to conduct parameter optimization, sensitivity, and uncertainty analysis. Although this framework was tested for SWAT, it can be readily applied to other environmental models. Ricciuto et al. (2008) performed a Bayesian calibration of a simple carbon cycle model at global-scale using the Monte Carlo Markov Chain (MCMC) technique. For the wellestablished biogeochemical model CENTURY, Liu et al. (2008b) adopted a nonlinear inversion technique-PEST (PEST, 2003) - to match the simulated net primary production (NPP) with Moderate-Resolution Imaging Spectroradiometer (MODIS) NPP. Chen et al. (2008) used another technique-smoothed ensemble Kalman Filter (SEnKF)-to achieve the model-data assimilation for the same model.

In this study, the primary objective is to develop automatic calibration (auto-calibration) for the General Ensemble Biogeochemical Modeling Systems-Erosion Deposition Carbon Model (GEMS-EDCM) (Liu et al., 2003b, 2004), at multiple (especially the regional) scales, using the widely-used SCE algorithm and the R package FME. The updated EDCM is named EDCM-Auto, which can be implemented to derive the optimal parameter values for each individual pixel. GEMS, which originally manages the spatial data and prepares input for EDCM, is modified to provide observation data for the auto-calibration procedure and include options to either save these derived pixel-based parameters by EDCM-Auto or further derive the county-land cover specific parameter values through aggregation (i.e., parameter post-process) before model application. The developed EDCM-Auto can accommodate multi-parameter and multi-objective (i.e., satisfying multiple model output variables such as grain yield, NPP, and biomass) calibration and deal with land-cover changes. In a case study, however, we adopted the most sensitive parameter (i.e., maximum potential primary productivity) to demonstrate how the EDCM-Auto works for model auto-calibration due to the availability of observation data (grain yield for croplands and MODIS NPP for other land covers) at the regional scale.

\section{Materials and methods}

\subsection{GEMS-EDCM description}

\subsubsection{GEMS description}

The GEMS was developed by the U. S. Geological Survey (USGS) to provide spatially explicit biogeochemical simulations over large areas via integrating well-established ecosystem biogeochemical models and various spatial databases (Liu et al., 2004). GEMS is a new type of land-use land-cover change (LULCC)-oriented, regional-level biogeochemical simulation system assimilating spatially dynamic databases such as climate, land cover, management, and disturbances, etc. GEMS has two major components: Input/output database management and multiple encapsulated ecosystem models. As an interface and platform, GEMS framework assists users with getting standardized data into and out of the biogeochemical models that are staged on the GEMS platform. Fig. 1 shows the schematic diagram of the GEMS model.

The current GEMS has encapsulated multiple site-scale biogeochemical models such as the CENTURY model (Parton et al., 1987, 1994), the EDCM model (Liu et al., 2003b), and the spreadsheet or paint-bynumber model (PBN) (Liu et al., 2012a). Additional models can be added into the GEMS framework and share common input data layers. GEMS can drive these models simultaneously to perform ecosystem dynamics simulation over time and space, and it has been successfully used to simulate carbon dynamics (e.g., $\mathrm{CO}_{2}$ and $\mathrm{CH}_{4}$ fluxes and changes of carbon pools) in vegetation and soil at various spatial scales and for different regions (Dieye et al., 2012; Liu et al., 2008a, 2011; Tan et al., 2005, 2009, 2010; Zhao et al., 2010a,b).

Technically, the GEMS framework has relatively few pre-requisites that include HDF5 and netCDF4 libraries as well as the GNU XML parser libraries. Individual models are linked into the framework at compile time as standard $\mathrm{C}$ or $\mathrm{C}++$ function calls. By using the control file which defines the input and output variables and other settings (e.g. the sampling rate, the size of the moving widow, and the simulation period), a user can invoke any of the models with a single executable. The major function of GEMS can be described briefly as follows:

1) Reads various spatiotemporal database (climate, land cover, etc.) with standardized NetCDF4 format into data arrays and an attribute structure and pass them into a specific model library (e.g., EDCM library) which is responsible for writing out the required input files for a model (EDCM),

2) Drives a model (e.g., EDCM, CENTURY, and PBN) run with or without data assimilation followed by opening a series of output netCDF4 files and provides a function to write data arrays to those output files,

3) Utilizes a "moving window" to break up requested model tins into manageable sizes given hardware resources, yet in the end provides output files that are continuous for the entire requested geographical area.

4) Implements sampling approach to speed model simulations in addition to conventional approach that supports wall-to-wall or per-pixel only simulations. With the sampling approach, users can choose different sampling densities to run GEMS to meet their needs.

\subsubsection{EDCM description}

EDCM (Liu et al., 2003b) is a modified version of the CENTURY model (version IV) (Parton et al., 1987, 1994). Although EDCM retains the basic input and output file structures of CENTURY, many changes have been made in input parameters and simulation algorithms of the underlying biogeochemical processes. First, EDCM uses up to ten soil layers to simulate the soil organic carbon (SOC) dynamics in the whole soil profile, instead of one single top-layer $(20-\mathrm{cm})$ structure of CENTURY. In each soil layer, EDCM characterizes the quantity and quality of SOC, following the practice used by CENTURY for the top soil layer. This treatment retains the proven applicability of CENTURY model for the topsoil layer and provides consistency between the top layer and the deeper layers in EDCM simulations. Second, EDCM can dynamically keep track of the evolution of the soil profile and carbon storage as influenced by soil erosion and deposition (Liu et al., 2003b), though CENTURY does not have the capability of simulating SOC dynamics in depositional environments. Third, instead of using a simple bucket hydrological sub-model of CENTURY, EDCM has improved the routine for simulating vertical water fluxes and soil moisture content to enhance the prediction of 


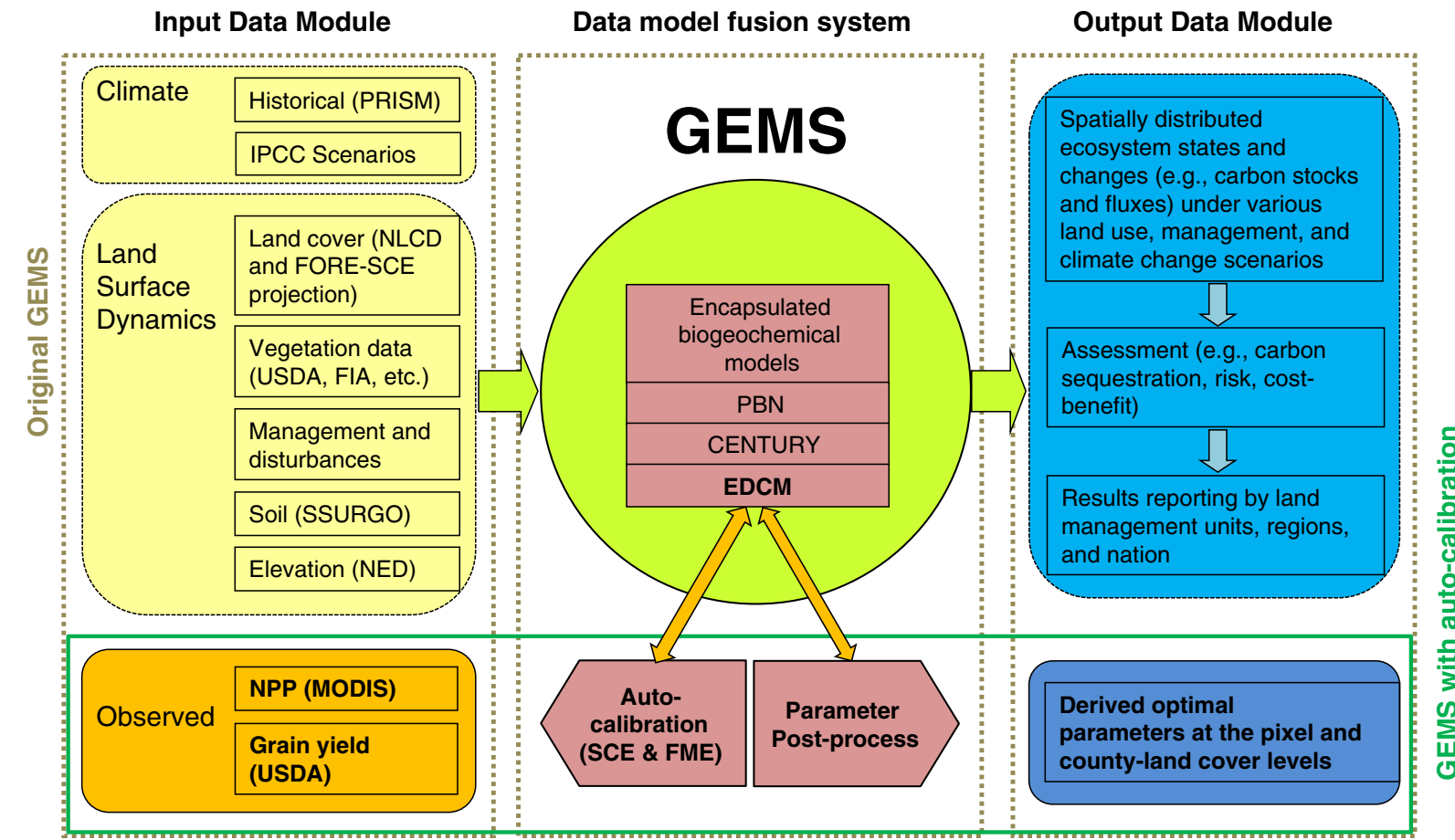

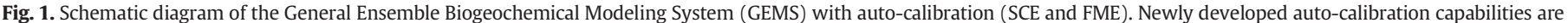
labeled in bold text.

ecosystem productivity and soil organic matter decay by introducing the stochastic procedures for better representation of diverse climate regimes (Liu et al., 2003b). Additionally, EDCM has incorporated the temporal improvement of crop yield based on the yield trends over 1866 to 2009 for 23 major crop species, indicating continuous improvement over the past century and is continuing into the future due to genetic engineering and improved management practices.

In brief, similar to CENTURY, EDCM is a process-based biogeochemical model which can simulate carbon and nitrogen cycles in diverse ecosystems at a monthly time step and take into account the impacts of land management and disturbances (Liu et al., 2003b, 2011; Tan et al., 2009; Zhao et al., 2010a).

\subsubsection{Model diagram, input, and output}

GEMS utilized a variety of input data layers for an ecological region (ecoregion) including climate for baseline (Parameter-elevation Regressions on Independent Slopes Model) (PRISM Climate Group, 2012) and projection (CFS) (Canadian Forest Service, 2012), the National Land Cover Database (NLCD 1992) (Homer et al., 2007) and projected land cover by the FORecasting SCEnarios of future land-cover (FORESCE) model (Sohl and Sayler, 2008; Sohl et al., 2007), soils (Soil Survey Geographic Database (SSURGO)) (USDA-NRCS, 2009), elevation (National Elevation Dataset (NED)) (Gesch, 2007; Gesch et al., 2002; USGS, 2012), land and forest management, and disturbances (see Fig. 1). Each of GEMS inputs was obtained from the published data source and most are converted to standard spatial $(250 \mathrm{~m})$ and temporal (monthly or yearly) resolutions (Liu et al., 2012b; Schmidt et al., 2011).

Although different biogeochemical models integrated in GEMS have some distinct output variables, their common output variables include net primary productivity (NPP), grain production, and dynamics of carbon pools of vegetation and soils for terrestrial ecosystems. Details about input data sources and format and output variables and format can be found in the USGS publication series (Liu et al., 2012a,b,c; Schmidt et al., 2011).

In terms of the data coverage, all the input data layers have been setup for the conterminous United States in a standard format (NetCDF), and time-series data cover a 59-year time frame from 1992 to 2050
(Liu et al., 2012b; Schmidt et al., 2011) except for the grain yield which is not available for the projection period.

\subsubsection{Modeling environment}

The GEMS models are executed on IBM rack-mounted cluster systems, including two six 3950 X5 servers and external disk storage. Each of the six servers is comprised of four eight-cores totaling four 32 processors per server. With threading enabled, 64 threads are available per server. In addition, pairs of servers are efficiently coupled together using IBM's implementation of Intel QuickPath Interconnect (QPI) technology, presenting a single system configuration of a 128 processor "cluster". Each component server of a cluster is running CentOS 5.6 x 86_64 bit, and has been configured with one-half TeraByte (TB) of memory per cluster to allow processing of ecoregion-sized datasets. To support both the large number of input data layers and output data products, each paired set of servers has been configured with a 6.5 TB of RAID storage capacity. This allows all the necessary input and output data layers to be staged on the server and utilized for all model simulations.

Although the spatial resolution for most GEMS input data layers is $250 \mathrm{~m}$, GEMS can provide options for full-resolution (wall-to-wall) simulations or systematic sampling (e.g., $10 \times 10$ sampling refers to sampling at 10-pixel interval in both horizontal and vertical directions, equivalent to $1 \%$ sampling rate) to increase throughput of simulations for regional modeling. The $10 \times 10$ systematic sampling rate has been demonstrated to produce statistically accurate results for reporting for a national-level assessment through comparison of the sampling results with the full-resolution simulations (Liu et al., 2012a; Zhu, 2011). This sampling approach can save substantial processing time for model calibration (Liu et al., 2012a) and application without sacrificing accuracy, and is also used for results presentation in the current study.

\subsection{Auto-calibration development}

\subsubsection{Background}

The SCE algorithm is a heuristic global optimization tool and has synthesized the best features of several existing algorithms, including a genetic algorithm and the concept of complex shuffling (Duan et al., 


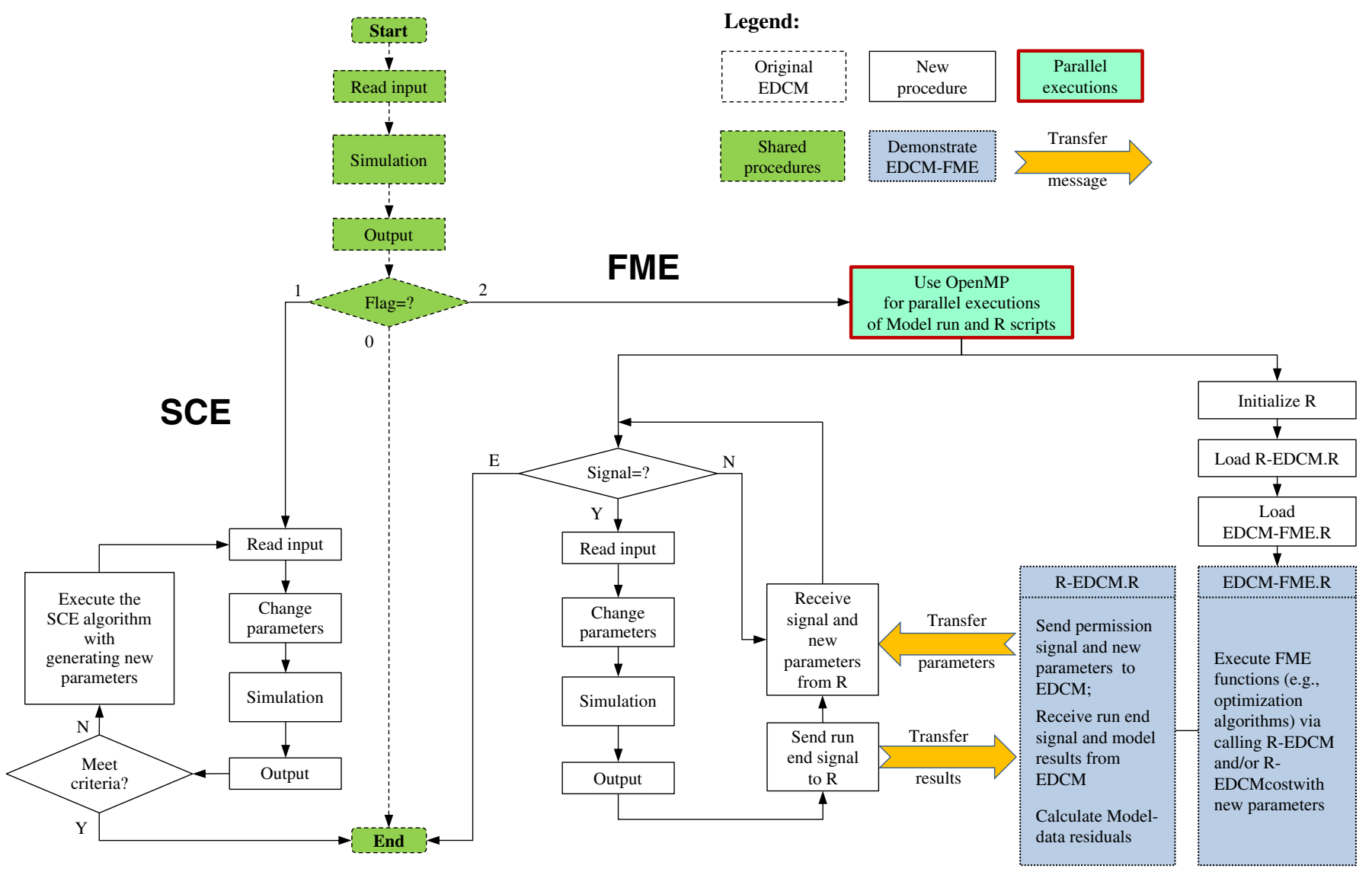

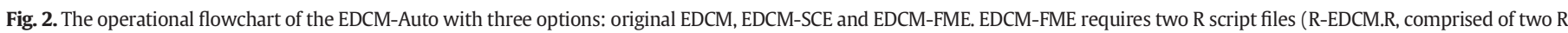
functions: R-EDCM and R-EDCMcost, and EDCM-FME.R which contains the major FME functions) (adapted from Wu and Liu (2012a,b)).

1992; Le Ngo et al., 2007). This algorithm conducts an efficient and robust search of the parameter space and has been widely applied for calibrating various numeric models (Brath et al., 2002; Duan et al., 1992; Eckhardt and Arnold, 2001; Le Ngo et al., 2007; Madsen, 2003). In particular, Green and van Griensven developed an auto-calibration tool (Green and van Griensven, 2008; van Griensven et al., 2006) for the widely-used hydrological/water quality model, Soil and Water Assessment Tool (SWAT) (Arnold et al., 1998; Neitsch et al., 2005), by incorporating the SCE algorithm (Duan et al., 1992).

The R-based FME is a flexible and complex modeling environment which includes algorithms for inverse modeling, in particular identifiability analysis (Brun et al., 2001), and sensitivity and Monte Carlo analysis (Haario et al., 2006; Laine, 2008). FME was successfully adapted for the SWAT model through the developed framework R-SWAT-FME (Wu and Liu, 2012a,b, 2014) to conduct the parameter identifiability, optimization, and sensitivity and uncertainty analysis. Wu and Liu (2012a) compared SCE and FME in a case study which demonstrated that both methods perform very well and are comparable to each other in deriving the optimal parameters.

\subsubsection{Wrapping EDCM with SCE and FME}

Although GEMS incorporates multiple biogeochemical models, the underlying EDCM was selected as an example to demonstrate the development of model auto-calibration in this study. In other words, SCE and FME were directly linked to EDCM instead of GEMS.

Based on our experience of running R-SWAT-FME and SWAT-SCE, the FME is powerful due to its multiple sensitivity and uncertainty analysis functions and instant visualization, but it runs slower due to the $\mathrm{R}$ script execution and interaction between the two languages: $\mathrm{R}$ and Fortran. In contrast, the SCE algorithm does not have multiple functions or powerful visualization and was coded in Fortran (i.e., the same language in which the model is coded), but it executes in less time. Considering their respective pros and cons, we proposed to wrap both SCE and FME with the EDCM to provide users alternative options for model calibration, although SCE is recommended for regional modeling (with intensive computation load) to make execution times practical.

EDCM, like SWAT, is a Fortran-based program. Therefore, we used the same methods for wrapping EDCM with SCE and FME as used for wrapping SWAT with SCE (Green and van Griensven, 2008; van Griensven et al., 2006) and FME (Wu and Liu, 2012a,b). Because the auto-calibration tool (SWAT-SCE) was coded in Fortran, it is not difficult to employ this tool for another Fortran-based model such as EDCM through moderate modification of the EDCM to accommodate its own parameter list to be optimized. Details of this technique can be found in the open source code of SWAT (http://swatmodel.tamu.edu/ software/swat-model/) and its auto-calibration manual (van Griensven, 2006). However, integrating EDCM with the R package (FME) needs additional effort because it involves two languages: Fortran and $R$.

As described by Wu and Liu (2012a), a Fortran-based model can be converted to be an R function using RFortran platform (Thyer et al.,

Table 1

Calibrated parameter values for a crop pixel with the corn-wheat rotation in Dane County, Wisconsin.

\begin{tabular}{lllll}
\hline Parameter & Parameter description & $\begin{array}{l}\text { Land cover } \\
\text { (crop species) }\end{array}$ & \multicolumn{2}{l}{$\begin{array}{l}\text { Calibrated } \\
\text { value }\end{array}$} \\
\cline { 3 - 5 } & & & $\mathrm{SCE}^{\mathrm{a}}$ & $\mathrm{FME}^{\mathrm{b}}$ \\
\hline PRDX & $\begin{array}{l}\text { Maximum potential production for a } \\
\text { specific vegetation and environment }\end{array}$ & Corn & 655.6 & 666.2 \\
& $\left(\mathrm{~g} / \mathrm{m}^{2} /\right.$ month $)$ & 269.3 & 208.4 \\
\end{tabular}

\footnotetext{
a SCE: shuffled Complex Evolution algorithm.
}

b FME: the Flexible Modeling Environment. 
2011), the Open Multi-Processing (OpenMP), and a customized signal transfer method. The other technique details for the implementation can be found in Wu and Liu (2012a) and their published software manual and package (Wu and Liu, 2012b). Because the developed R-SWATFME, which used SWAT as an example, provides a universal framework to wrap any Fortran/C ++ model with an R package we just applied that framework for the EDCM model, and Fig. 2 shows the operational flowchart of the developed EDCM-Auto. It is worth noting that there are two $\mathrm{R}$ script files (R-EDCM.R and EDCM-FME.R) specifically for connecting EDCM and FME. The R-EDCM.R file contains two R functions: one is REDCM function used for sending a new set of parameters (from FME to EDCM) and receiving model results (from EDCM to FME), and the other is R-EDCMcost used for calculating the model-data residual (sum of squared residuals (SSR)). With the support of these two functions, the optimization algorithm (i.e., FME functions) contained in the EDCMFME.R file can call the model freely and iteratively to reach the minimization of the SSR and obtain the optimal parameter values.

The developed model, named EDCM-Auto, contains two options, SCE and FME, for model calibration. Fig. 2 shows the operational flowchart of the EDCM-Auto, which also allows users to choose between 1) running the original EDCM model, 2) running the auto-calibration with SCE, and 3 ) running the auto-calibration with FME. In addition, the two optimization algorithms-SCE and FME-use the same objective function: minimizing the sum of squared residuals between EDCM simulation and observation.

\subsubsection{Target variables of model calibration}

It is usually necessary to define one or more model output variables to calculate the objective function during model auto-calibration. For biogeochemical models, NPP is a key variable because it represents the net amount of carbon being fixed through photosynthesis into an ecosystem and then directly regulates the storage and rates of change of organic carbon in vegetation and soil. Further, the prediction of the spatial and temporal change of NPP is critical for the simulation of carbon dynamics for a site or region. For croplands, however, grain yield is generally the primary variable of interest, which is ground survey-based. EDCM-Auto supports multi-objective (multiple variables such as NPP, grain yield, and biomass) calibration and incorporates the

$85^{\circ} \mathrm{W}$

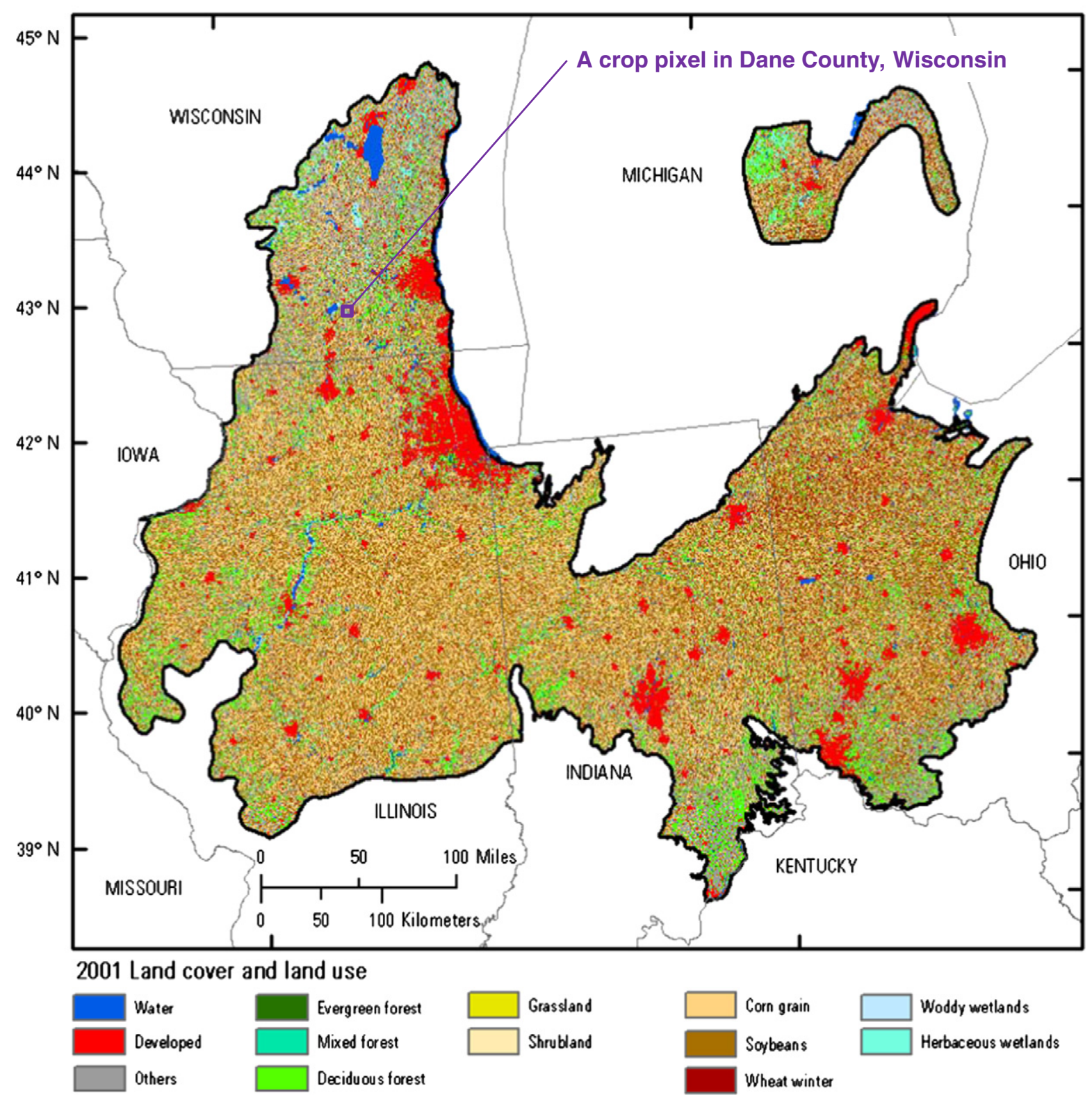

Fig. 3. Location and the land cover map (2001) of the Central USA Plains (Ecoregion 8.2). 
flexibility to add more target variables as long as the corresponding observations are available. Considering the limited availability of observation data at the regional level, we currently used readily available grain yield survey data and NPP remote sensing data (see Section 2.2.4).

\subsubsection{Observation data}

The schematic diagram of GEMS with auto-calibration, as shown in Fig. 1, illustrates that GEMS needs to be modified to provide observation data required by the EDCM-Auto. The observation data available for model calibration at the regional scale include county-based grain yield survey data published by U.S. Department of Agriculture (USDA) for crops and 250-m resolution MODIS NPP data (strictly not 'observation' but 'estimation' data) for other land cover types (Zhao et al., 2005). The reason for not using MODIS consistently for crops is that widely-used USDA grain yield data is relatively more accurate to calibrate the model for croplands. However, because the grain yield data is county-based, we assumed the grain yield is the same for all the pixels growing an individual crop species within a county. This approach may cause a small bias because it ignores the spatial heterogeneity of the growing conditions (e.g., soil) in a county; however, the parameter post-processes (aggregating at the county level) may meliorate this situation through applying the aggregated parameters.

The national USDA grain yield data was collected for a 39-year (1970-2009) period, but the recent 14-year (1996-2009) data were converted to the standard netCDF format for use when the USGS Land Carbon Project was initiated, and the MODIS NPP data was also converted to this format, which covers a 10-year period (2001-2010).

\subsubsection{Parameters to be optimized}

In EDCM and CENTURY, calculation algorithms for NPP use the concept of potential primary productivity (PPP) (Liu et al., 2003a). The PPP is the optimal primary productivity a system can reach without limitation from controlling variables; whereas NPP depends on both PPP and the time-varying limiting factors such as moisture, temperature, and nutrients (Liu et al., 2003a). Moreover, the PPP of a given ecosystem is a parameter (named as PRDX) which has both genetic and environmental components, and is the foremost parameter used to calibrate the plant production for different species, environments, and varieties (USDA, 1993). Therefore, the most sensitive parameter, PRDX, was selected as the parameter to be calibrated to constrain ecosystem production for demonstrating how the EDCM-Auto functions (Table 1), although more parameters are allowed to be incorporated for calibration. Some input parameters such as soil physical properties and forest mortality have been reflected in the input database which is spatially heterogenic, whereas other important ones such as soil organic carbon decomposition rates for each carbon pool and NPP allocation rates between biomass pools were used as suggested by CENTURY (default parameters).

In addition, it is common to have different land covers between years (e.g., land cover changes and crop rotations) for a single pixel, and the parameter PRDX is heavily crop dependent-its value or magnitude can be very different between crop species. Thus, the developed EDCM-Auto can track the land-cover changes including crop rotation over time and derive the optimal PRDX for each land-cover type simulated. This function is demonstrated for a crop pixel with a cornwheat rotation in a case study (see results in Section 4.1). Consideration of land cover changes leads to a hybrid calibration type among singleor multi-parameter and single- or multi-objective calibrations. For example, it is single-parameter and single-objective calibration for pixels with unique land cover or crop species. Instead, it can be multi-parameter (one PRDX for a specific land cover/crop species) and multi-objective (grain yield and/or NPP for all land covers growing on a pixel along time) calibrations for pixels with land cover change including crop rotation. This is because either grain yield or NPP of different species would be involved in a pure crop or non-crop land cover change; whereas both grain yield
Table 2

Evaluation of model performance in annual grain yield simulation during the 10-year calibration (1996-2005) and 5-year validation (2006-2010) periods for the crop pixel with corn-wheat rotation in Dane County, Wisconsin.

\begin{tabular}{|c|c|c|c|c|c|c|}
\hline \multirow[t]{2}{*}{ Method } & \multirow[t]{2}{*}{ Period } & \multicolumn{2}{|l|}{ Mean $^{a}$} & \multirow[t]{2}{*}{$\mathrm{PB}^{\mathrm{b}}(\%)$} & \multirow[t]{2}{*}{$\mathrm{R}^{2 \mathrm{c}}$} & \multirow[t]{2}{*}{ RMSE } \\
\hline & & Observed & Simulated & & & \\
\hline \multirow[t]{2}{*}{ SCE } & Calibration & 296.17 & 292.60 & -1.21 & 0.92 & 28.39 \\
\hline & Validation & 285.04 & 318.80 & 11.84 & 0.87 & 48.56 \\
\hline \multirow[t]{2}{*}{ FME } & Calibration & 296.17 & 292.15 & -1.36 & 0.94 & 24.28 \\
\hline & Validation & 285.04 & 309.80 & 8.69 & 0.85 & 37.09 \\
\hline
\end{tabular}

a The unit for grain yield is $\mathrm{g} C / \mathrm{m}^{2} / \mathrm{yr}$.

b PB: percent bias.

c $\mathrm{R}^{2}$ : Coefficient of Determination.

d RMSE: Root Mean Square Error, with a unit of $\mathrm{g} \mathrm{C} / \mathrm{m}^{2} / \mathrm{yr}$.

and NPP would be involved for land cover change between a crop and a non-crop.

\subsubsection{Parameter post-process}

Because EDCM (like CENTURY) is a site scale model, EDCM-Auto can readily derive the optimal parameters for each individual pixel. We developed one more function for GEMS-parameter post-process-with which the pixel-based parameter values can be converted to the land cover specific parameter values through aggregation at the county level (Fig. 1). This means that a single parameter value for each individual crop species within a county will also be derived. Thus, the EDCM-Auto can implement the auto-calibration at the pixel/site scale and facilitate model application at the regional scale with two parameter-applying options (two-scale parameter): pixel-level parameter and county-land cover based parameter.

\section{Case study}

To examine the developed auto-calibration function at multiple scales, we applied the EDCM-Auto for a single pixel and an entire ecoregion containing the single pixel.

\subsection{A single pixel}

We selected a crop pixel with a corn-wheat rotation in Dane County (Wisconsin), as shown in Fig. 3, to demonstrate the capability of EDCMAuto in handling land-cover change such as crop rotation. During a 15-year (1996-2010) period, corn was mainly grown on this pixel, except for year 2003, 2004, 2007, and 2009 when wheat was cultivated.

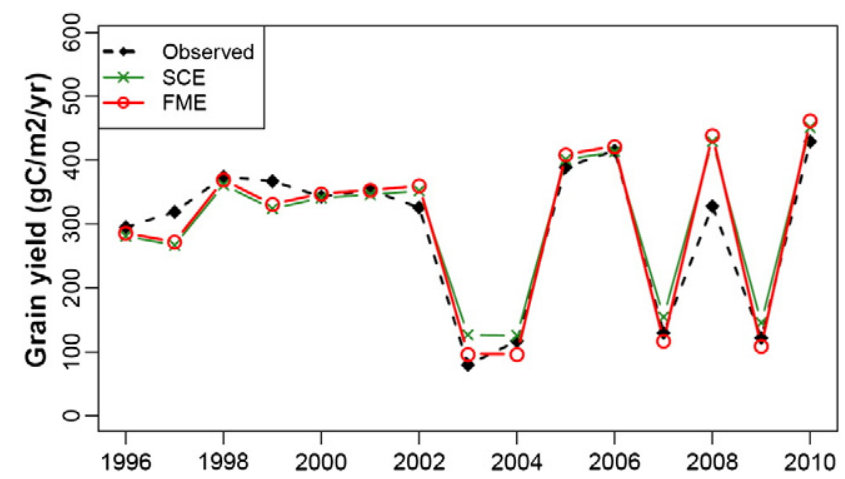

Fig. 4. Observed grain yield versus simulations with calibrated parameters by SCE and FME during the 10-year (1996-2005) calibration and 5-year (2006-2010) validation for a crop pixel located in Dane County, Wisconsin. The crop species grown on this pixel was corn except for year 2003, 2004, 2007, and 2009 when wheat was grown. 


\subsection{An ecoregion}

The Central USA Plains (Fig. 3), Level II ecoregion (Omernik, 1987) has an area of 253,665 $\mathrm{km}^{2}$, and this region belonged to the Wisconsin and Illinoisan glacier, except for the north-central part which was covered by the glacial lake Maumee. This ecoregion is characterized by rolling till plain with local end moraines and lacustrine, calcium enriched soils (Cormier et al., 2000). The climate is generally humid and cool with mean annual precipitation ranging from 760 to $1100 \mathrm{~mm}$ and mean annual temperature varying from 7 to $13{ }^{\circ} \mathrm{C}$ (Wiken et al., 2011). The daily minimum temperature in winter can be as low as $-12{ }^{\circ} \mathrm{C}$. This ecoregion contains some larger urban areas such as Chicago (Illinois) and Detroit (Michigan), and several mid-size and smaller cities and towns. Forest with mixed oak-hickory associations are common; however, elm, ash, beech, maple are also major tree species with more prairie to the west. Cropland is extensive with corn, wheat, and soybean along with dairy industry (Commission for Environmental Cooperation, 1997, 2008).

\subsection{Model implementation}

The key input of land-cover database (NetCDF format) is spatiallyexplicit and at annual time step, thus the GEMS framework can track the land cover changes (including crop rotation) well for any individual pixel and pass this information together with other management practices and disturbances into the CENTURY or EDCM schedule file, which records all the events (e.g., land cover change, plant, harvest, fire, and cutting) on a pixel. The corn-wheat rotation in our first case study is just an example of all kinds of land cover changes or crop rotations (which may involve more than two species for some pixels).

As described previously (Sections 2.1.3 and 2.2.4), the input data layers span 59 years (1992-2050), but the observed grain yield and NPP data used for model auto-calibration cover 14 years (1996-2009) and 10 years (2001-2010), respectively, at the national level. For the sake of consistence and uniformity in the regional implementation of EDCM-Auto, we used the same 5-year (2001-2005) calibration and 5-year (2006-2010) validation periods for all pixels (including crop
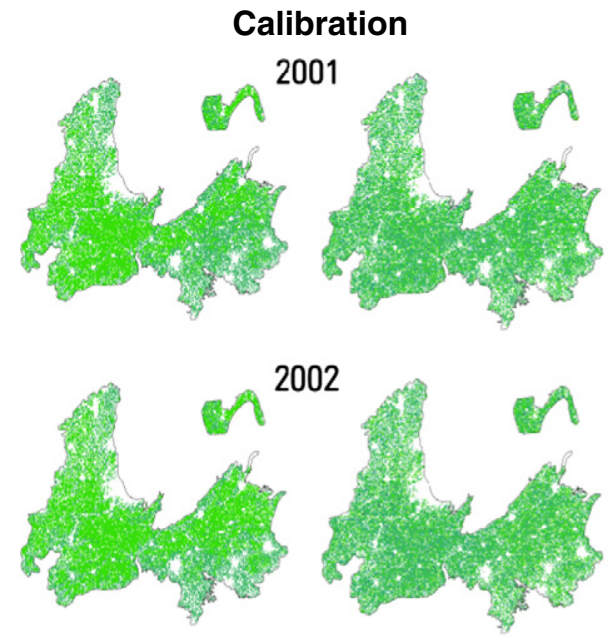

2002
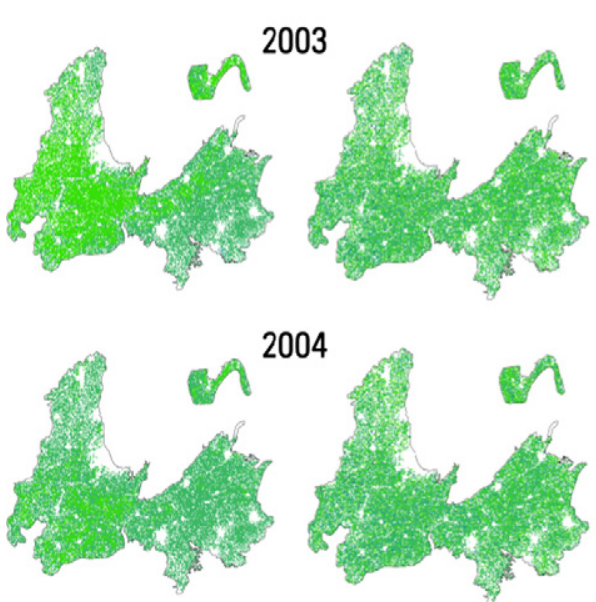

2004

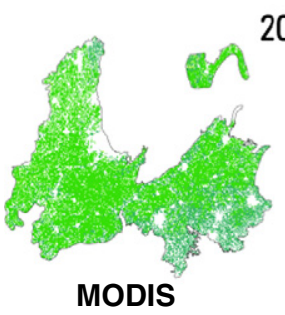

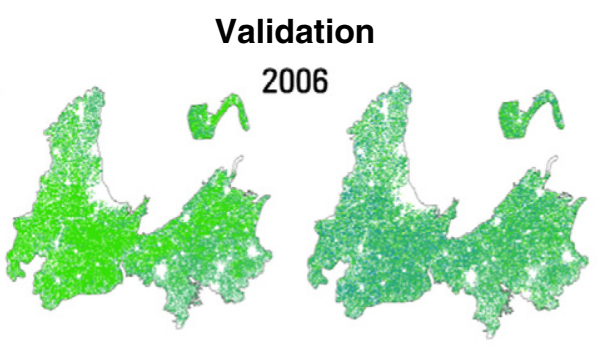

2007

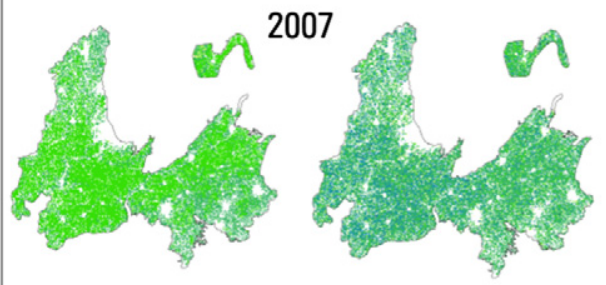

2008

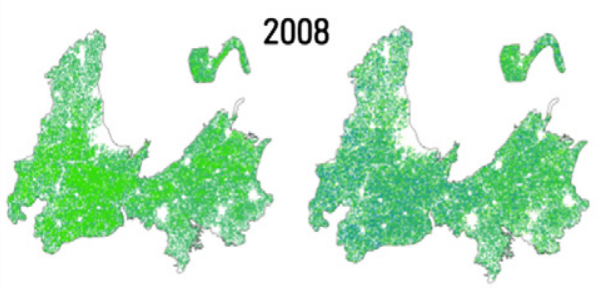

2009

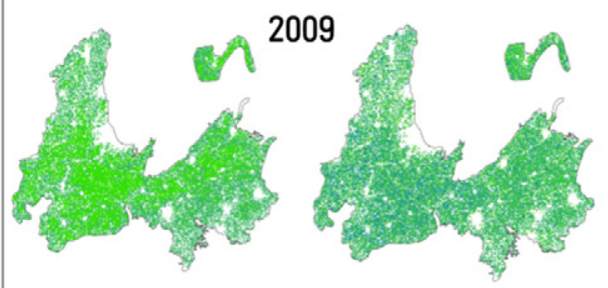

NPP g C/m²/yr

2010

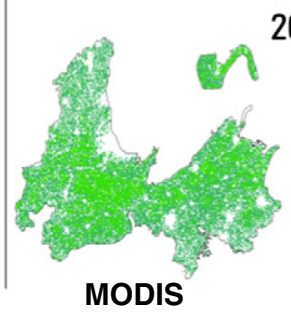

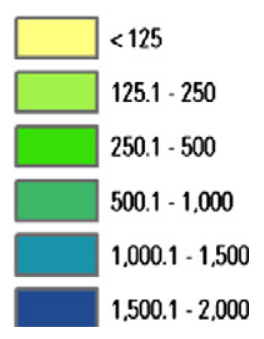

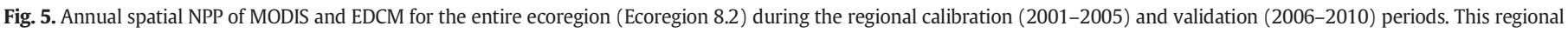

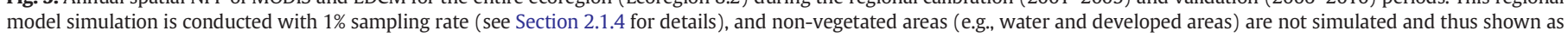
no data. 

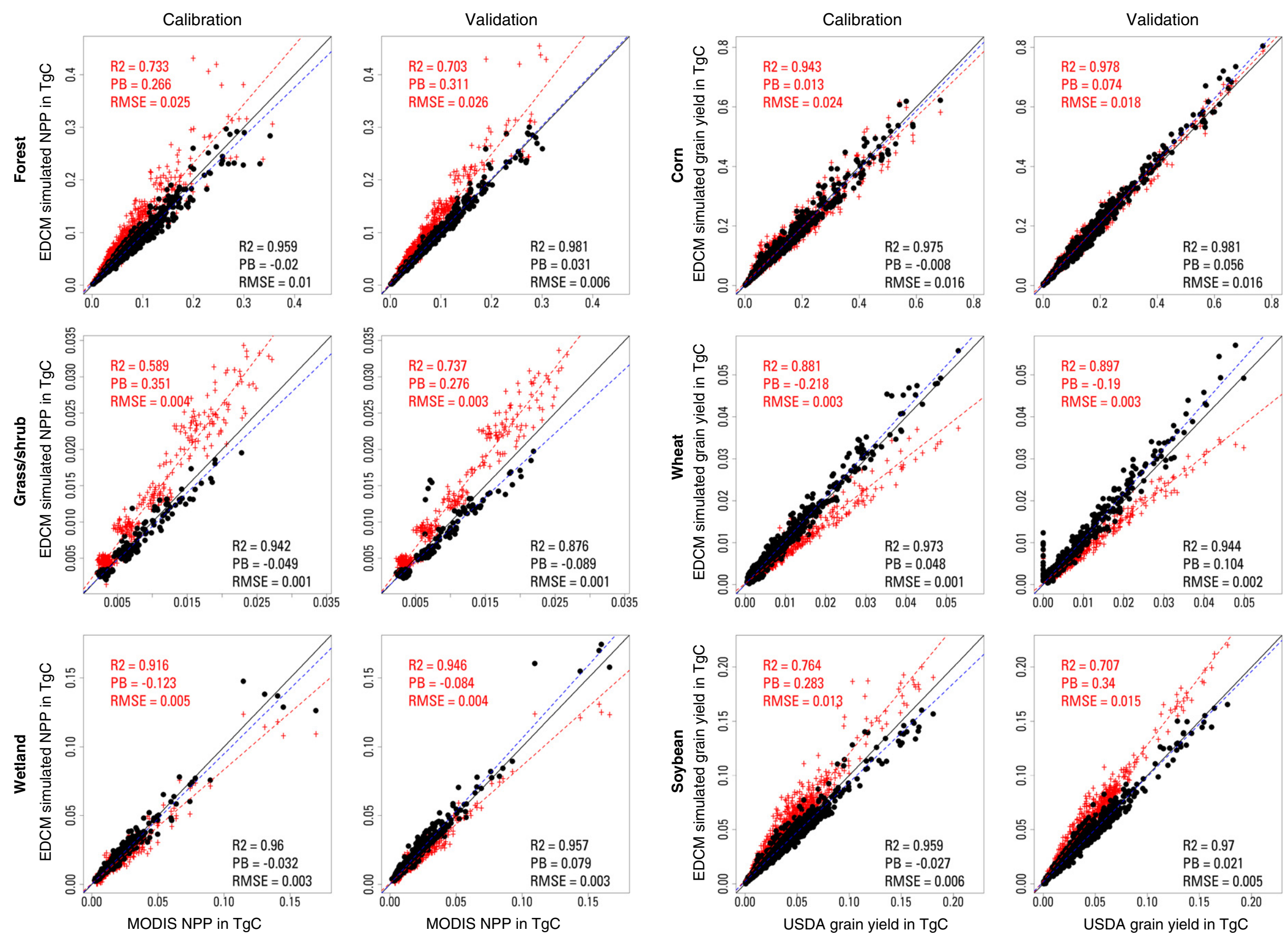

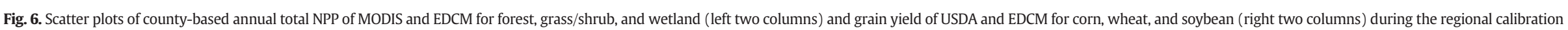

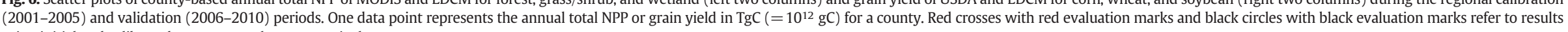
using initial and calibrated parameter values, respectively. 
and non-crop pixels), although the crop yield data for 2010 is missing. For the specific crop pixel in Dane County (Wisconsin), however, we used a 10-year calibration (1996-2005) and a 5-year (2006-2010) validation.

\section{Results and discussion}

\subsection{Pixel-scale model evaluation}

In our case study, we used a single pixel first to examine the model auto-calibration function before applying it for an entire ecoregion (presented in the following section). By implementing the EDCMAuto for e same crop pixel, we compared the two auto-calibration algorithms-SCE and FME. The derived optimal parameter values by SCE and FME are listed in Table 1. The graphical comparisons of annual simulated grain yield (including corn and wheat) against those observed during the 10-year (1996-2005) calibration and the 5-year (2006-2010) validation periods are presented in Fig. 4, suggesting a general agreement between simulations and observations. We also used a set of statistical measures including the percent bias (PB) which measures the average difference between simulations and observations, coefficient of determination $\left(\mathrm{R}^{2}\right)$, and Root Mean Square Error (RMSE), to scale the model performance and the results are listed in Table 2. During the calibration period, SCE had a lower PB, but FME was a little better in $\mathrm{R}^{2}$ and RMSE. For the validation, SCE overestimated grain yields by $11.84 \%$, while FME also over-estimated them but with a lower PB of 8.69\%. Although SCE performed a little better in terms of $\mathrm{R}^{2}$, FME indicated a less error (RMSE) (Table 2). Based on the performance ratings of Moriasi et al. (2007), the monthly simulations can be evaluated as "good" $\left(\mathrm{R}^{2}>0.65\right.$ and $\left.|\mathrm{PB}| \leq 15 \%\right)$ for both calibration and validation periods. Overall, the simulated grain yields with the two sets of optimal parameters from SCE and FME behaved very similarly (Table 2 and Fig. 4) and matched well with the observations during the calibration and validation periods except for a big discrepancy in corn yield for 2008. Comparing the inputs for year 2006 and 2008 when corn was growing, the average precipitation was nearly the same ( 6.9 and $7.0 \mathrm{~cm} / \mathrm{month}$ ) and no difference was found in managementpractice input. Thus, it seemed 'reasonable' to have similar corn yields for these two years in terms of 'modeling' due to similar inputs. Therefore, we think the substantial over-estimation of corn yield for 2008 may be attributed to the misrepresentation of precipitation, which is likely because the real precipitation falling on this pixel $(250 \mathrm{~m}$ by $250 \mathrm{~m})$ may be less than the downscaled values from weather gages far from this pixel considering the spatial heterogeneity of precipitation.

This pixel-scale case study demonstrates that the extended model is flexible to handle land-cover changes for each pixel, which is very common in the real world, when implementing model calibration. The evaluation of model performance (Fig. 4) indicates that both SCE and FME are comparable and performed well for inverse modeling with acceptable results.

\subsection{Regional-scale model evaluation}

After the successful application for a single pixel, we applied the EDCM-Auto for the entire Central USA Plains ecoregion to examine its performance. Regional modeling with $250 \mathrm{~m}$ resolution is timeconsuming and activating the model calibration algorithm can cost even more time; we selected SCE, whose execution speed is superior to FME, to implement the model auto-calibration for the regional level with a sampling rate of $1 \%$ (see Section 2.1.4).

As shown in Fig. 3, there are a number of land-cover types in this ecoregion, and the EDCM-Auto can deal with all these specific types except for water and developed areas which are skipped by the model. During the model auto-calibration, USDA grain yield data were used to derive the optimal values of PRDX for crop pixels and MODIS NPP was used for non-crop pixels (see Section 2.2.4). Considering the
USDA grain yield data is county-based instead of pixel-based, we used the uniform variable NPP to present a spatial comparison at pixel level between observation (e.g., MODIS NPP) and simulation (EDCM NPP), as shown in Fig. 5. The visual comparison indicates the model performed reasonably well in capturing the spatial pattern of NPP at the regional scale, although it is not fair to inspect NPP for crop pixels with this figure. We admitted that there are still some discrepancies between MODIS and simulation in some parts of this ecoregion and in some years (2002 and 2005). This may come from modeling uncertainties as both MODIS and EDCM NPP are estimations and mismatch of land cover types between model input data (250-m resolution) and the real world as we noticed for some pixels during model debug.

The county-based scatter plots shown in Fig. 6 clearly demonstrate the good model performance in NPP simulation for non-crop land covers (forest, grass/shrub, and wetland pixels) and grain yield simulation for crop land covers (corn, wheat, and soybean). It is more preferable to use Fig. 6 (instead of Fig. 5 which was just for an auxiliary approach at pixel level) to evaluate the model performance considering the fact that USDA grain yield is county based and was used for model calibration on crop pixels. Fig. 6 shows two sets of results: one is for using initial parameter values (red crosses) and the other is for using calibrated values (black circles). Although initial parameter values are fixed for each land cover type, the calibrated values varied spatially, and thus a distribution of them (county-land cover based values) was presented in Fig. 7, showing the difference between assumed and calibrated values. From the result comparison shown in Fig. 6, calibration did improve the model performance in terms of $\mathrm{R}^{2}, \mathrm{~PB}$ and RMSE. Take the validation for forest as an example, the bias has been reduced from $31 \%$ to $3 \%$, and $\mathrm{R}^{2}$ was elevated from 0.70 to 0.98 .

We also compared the model performance for each ecosystem (crop type) at the regional scale as shown in Fig. 8, which illustrates that simulations of annual NPP and grain yield per unit of area (i.e., $\mathrm{kg} \mathrm{C} / \mathrm{m}^{2}$ ) are also in good agreement with the observations (i.e., MODIS NPP and USDA grain yield).

The evaluation of the model performance for this regional case study (Figs. 5, 6, and 8) demonstrates that incorporating the remotely sensed

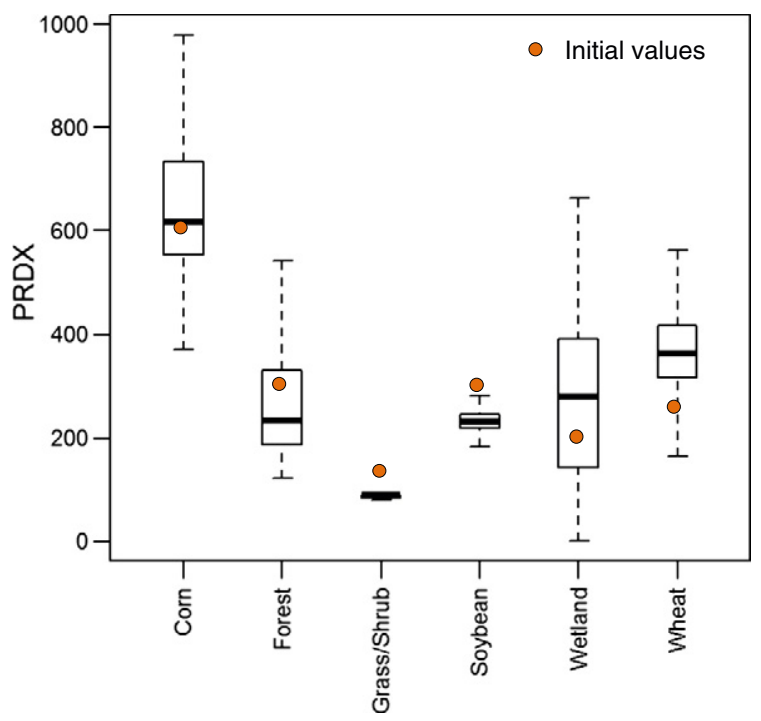

Fig. 7. Comparison of the initial and calibrated parameter values for each land cover in the Central United States Plains. The calibrated parameter values vary spatially, and thus are shown as a boxplot distribution among all the counties in this region. The calibrated parameter values vary spatially, and thus are shown as a boxplot distribution among all the counties in this region. The top end of the whisker shows the maximum value without exceeding the upper fence $\left(\mathrm{F}_{\mathrm{U}}=\mathrm{H}_{\mathrm{U}}+1.5 \times \mathrm{H}_{\text {spread }}\right)$, upper hinge $\left(\mathrm{H}_{\mathrm{U}}\right)$ is the $3 \mathrm{rd}$ Quantile, the bold line drawn through the box is the median value (2nd Quantile), lower hinge $\left(\mathrm{L}_{\mathrm{U}}\right)$ is the $1 \mathrm{st}$ Quantile, the bottom end of the whisker is the minimum value but no less than the lower fence $\left(\mathrm{F}_{\mathrm{L}}=\mathrm{H}_{\mathrm{L}}-1.5 \times \mathrm{H}_{\text {spread }}\right)$, and the rectangle box indicates the hinge spread $\left(\mathrm{H}_{\text {spread }}=\mathrm{H}_{\mathrm{U}}-\mathrm{H}_{\mathrm{L}}\right)$. 

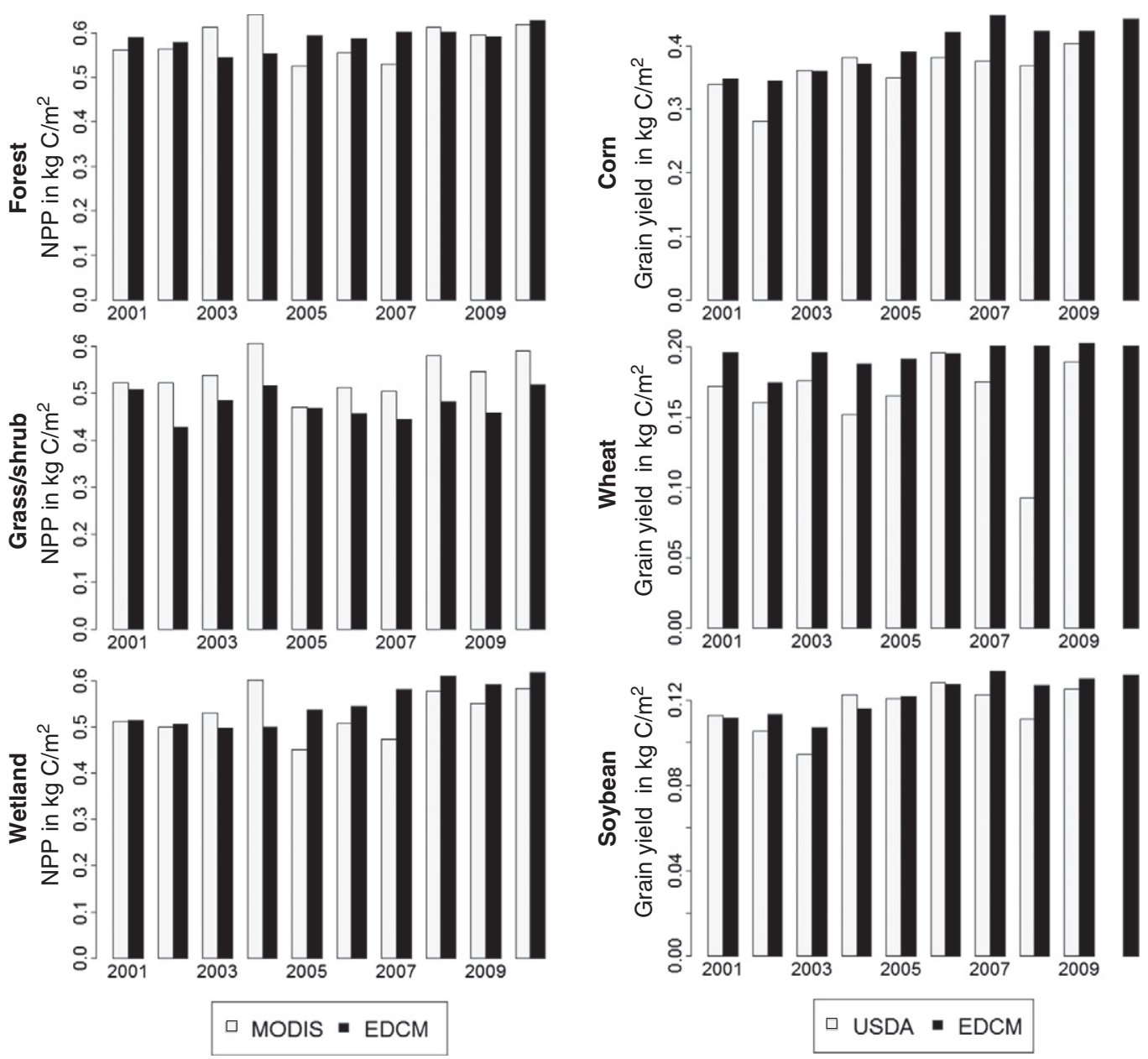

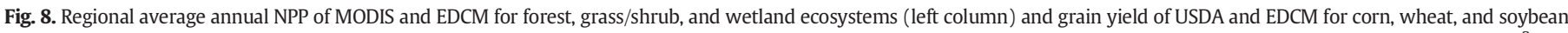

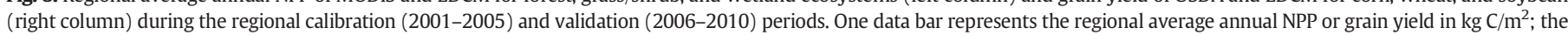
USDA grain yield data was missing for 2010 at the regional level.

data (NPP) into automatic model calibration provides a feasible approach and a good example for attempting to solve the challenging issue-model calibration/validation at large scale-in the ecological modeling field.

Overall, both case studies justify that the developed EDCM-Auto can be successfully applied for model auto-calibration at multiple (pixel and region) scales and can handle land-cover changes (including crop rotations) as well. In addition, the case studies indicate that our developed package worked for a variety of ecosystems such as crop (corn, wheat, soybean), forest, grass/shrub, and wetland. However, estimating uncertainty of simulation results due to parameter uncertainty would be a concern when the number of parameters increases, which will be a good subject of further study.

\section{Conclusions}

In this study, we developed the auto-calibration function for the biogeochemical model EDCM by introducing the widely-used optimization algorithms: the Shuffled Complex Evolution (SCE) and the Flexible Modeling Environment (FME). Our case study demonstrates that the developed EDCM-Auto (with SCE and FME available for EDCM) can be successfully applied for model calibration at multiple scales (pixel and region) with satisfactory results in simulation of NPP and grain yield. Although both SCE and FME work behaved similarly, the former is recommended for model calibration over large regions with high computation load because it runs faster than the latter, which instead can support other R functionalities such as instant visualization. This extended model is also flexible to deal with land-cover changes and to optimize multiple parameters with multiple objectives (e.g., NPP, grain yield, and biomass) as long as observations are available. In particular, the method of linking SCE and FME to an ecological model (especially linking an $\mathrm{R}$ package to a non-R model as we presented) can be useful and valuable for others who would like to utilize these two techniques for their own ecological models. In fact, applying our method, which was used for the hydrological model SWAT first, to the biogeochemical model EDCM justifies the generalizability of our approaches. Additionally, investigating parameter sensitivity and uncertainty also attracts much attention especially when the number of parameters to be calibrated increases, and this would be reflected in our further studies.

\section{Acknowledgments}

This study was funded by the NASA Land Cover and Land Use Change Program, Land Carbon Project (GEMS Modeling), and U.S. Geological Survey Geographic Analysis and Monitoring (GAM) Program. The work was performed under USGS contract G08PC91508. Any use of trade, firm, or product names is for descriptive purposes only and does not imply endorsement by the U.S. Government. We thank Lei Ji for performing internal review and Sandra Cooper for further check. We are also grateful to the two anonymous reviewers for their constructive comments and suggestions. 


\section{References}

Arnold, J.G., Srinivasan, R., Muttiah, R.S., Williams, J.R., 1998. Large area hydrologic modeling and assessment-part 1: model development. J. Am. Water Resour. Assoc. 34, 73-89.

Beven, K.J., 2001. Rainfall-Runoff Modelling. John Wiley \& Sons, Chichester 360.

Brath, A., Montanari, A., Toth, E., 2002. Analysis of the Effects of Different Scenarios of Historical Data Availability on the Calibration of a Spatially-Distributed Hydrological Model, 27th General Meeting of the European-Geophysical-Society. 232-253 (Nice, France).

Brun, R., Reichert, P., Kunsch, H.R., 2001. Practical identifiability analysis of large environmental simulation models. Water Resour. Res. 37, 1015-1030.

Canadian Forest Service, 2012. Climate Change Scenarios Data: Canadian Forest Service Database. http://cfs.nrcan.gc.ca/projects/3/5 (Accessed May 31, 2012).

Chen, M., Liu, S., Tieszen, L.L., Hollinger, D.Y., 2008. An improved state-parameter analysis of ecosystem models using data assimilation. Ecol. Model. 219, 317-326.

Commission for Environmental Cooperation, 1997. Ecological Regions of North America: Toward a Common Perspective. In: McGinley, M. (Ed.), Commission for Environmental Cooperation, Montreal, Canada, p. 71.

Commission for Environmental Cooperation, 2008. Ecoregions of North America-Level II (CEC). In: McGinley, M. (Ed.), Environmental Information Coalition. National Council for Science and the Environment, Washington D.C.

Cormier, S.M., Smith, M., Norton, S., Neiheisel, T., 2000. Assessing ecological risk in watersheds: a case study of problem formulation in the Big Darby Creek watershed, Ohio, USA. Environ. Toxicol. Chem. 19, 1082-1096.

Dieye, A.M., Roy, D.P., Hanan, N.P., Liu, S., Hansen, M., Toure, A., 2012. Sensitivity analysis of the GEMS soil organic carbon model to land cover land use classification uncertainties under different climate scenarios in Senegal. Biogeosciences 9 , 631-648.

Duan, Q.Y., Sorooshian, S., Gupta, V., 1992. Effective and efficient global optimization for conceptual rainfall-runoff models. Water Resour. Res. 28, 1015-1031.

Eckhardt, K., Arnold, J.G., 2001. Automatic calibration of a distributed catchment model. J. Hydrol. 251, 103-109.

Gesch, D.B., 2007. The National Elevation Dataset. In: Maune, D. (Ed.), American Society for Photogrammetry and Remote Sensing, Bethesda, Maryland, pp. 99-118.

Gesch, D.B., Oimoen, M., Greenlee, S., Nelson, C., Steuck, M., Tyler, D., 2002. The National Elevation Dataset Photogrammetric Engineering and Remote Sensing. 68 5-11.

Goldberg, D., 1989. Genetic Algorithms in Search, Optimization and Machine Learning. Addison-Wesley, Reading, Massachusetts, USA.

Green, C.H., van Griensven, A., 2008. Autocalibration in hydrologic modeling: using SWAT2005 in small-scale watersheds. Environ. Model Softw. 23, 422-434.

Gupta, H.V., Sorooshian, S., Yapo, P.O., 1999. Status of automatic calibration for hydrologic models: comparison with multilevel expert calibration. J. Hydrol. Eng. 4, 135-143.

Haario, H., Laine, M., Mira, A., Saksman, E., 2006. DRAM: efficient adaptive MCMC. Stat. Comput. 16, 339-354.

Holland, J., 1975. Adaptation in Natural and Artificial Systems. University of Michigan Press, Ann Arbor, Michigan, USA

Homer, C., Dewitz, J., Fry, J., Coan, M., Hossain, N., Larson, C., et al., 2007. Completion of the 2001 National Land Cover Database for the conterminous United States. Photogramm. Eng. Remote. Sens. 73, 337-341.

Janssen, P.H.M., Heuberger, P.S.C., 1995. Calibration of process-oriented models. Ecol. Model. 83, 55-66.

Juston, J., Andren, O., Katterer, T., Jansson, P.-E., 2010. Uncertainty analyses for calibrating a soil carbon balance model to agricultural field trial data in Sweden and Kenya. Ecol. Model. 221, 1880-1888.

Laine, M., 2008. Adaptive MCMC methods with applications in environmental and geophysical models. Finn. Meteorol. Inst. Contrib. 69.

Larssen, T., Hogasen, T., Cosby, B.J., 2007. Impact of time series data on calibration and prediction uncertainty for a deterministic hydrogeochemical model. Ecol. Model. 207, 22-33.

Le Ngo, L., Madsen, H., Rosbjerg, D., 2007. Simulation and optimisation modelling approach for operation of the Hoa Binh reservoir, Vietnam. J. Hydrol. 336, 269-281.

Liu, J.X., Liu, S.G., Loveland, T.R., Tieszen, L.L., 2008a. Integrating remotely sensed land cover observations and a biogeochemical model for estimating forest ecosystem carbon dynamics. Ecol. Model. 219, 361-372.

Liu, S., Anderson, P., Zhou, G., Kauffman, B., Hughes, F., Schimel, D., et al., 2008b. Resolving model parameter values from carbon and nitrogen stock measurements in a wide range of tropical mature forests using nonlinear inversion and regression trees. Ecol. Model. 219, 327-341.

Liu, S., Bliss, N., Sundquist, E., Huntington, T.G., 2003a. Modeling carbon dynamics in vegetation and soil under the impact of soil erosion and deposition. Glob. Biogeochem. Cycles 17, 1074

Liu, S., Liu, J., Young, C. Werner, J.M., Wu, Y., Li, Z., et al., 2012a. Chapter 5: Baseline Carbon Storage, Carbon Sequestration, and Greenhouse-Gas Fluxes in Terrestrial Ecosystems of the Western United States. In: Zhu, Z., Reed, B. (Eds.), U.S. Geological Survey, Reston, Virginia, pp. 45-63 (Available online at http://pubs.usgs.gov/pp/1797/pdf/ pp1797 Chapter5.pdf)

Liu, S., Oeding, J., Tan, Z., Schmidt, G.L., Dahal, D., 2012b. Chapter 4: Major LandManagement Activities and Natural Disturbances Considered in this Assessment. In: Zhu, Z., Reed, B. (Eds.), U.S. Geological Survey, Reston, Virginia, pp. 45-63 (Available online at http://pubs.usgs.gov/pp/1797/pdf/pp1797_Chapter4.pdf).

Liu, S., Wu, Y., Young, C., Dahal, D., Werner, J.M., Liu, J., et al., 2012c. Chapter 9: Projected Future Carbon Storage and Greenhouse-Gas Fluxes of Terrestrial Ecosystems in the Western United States. In: Zhu, Z., Reed, B. (Eds.), U.S. Geological Survey, Reston, Virginia, pp. 109-124 (Available online at http://pubs.usgs.gov/pp/1797/pdf/pp1797_Chapter9. pdf).
Liu, S.G., Bliss, N., Sundquist, E., Huntington, T.G., 2003b. Modeling carbon dynamics in vegetation and soil under the impact of soil erosion and deposition. Glob. Biogeochem. Cycles 17.

Liu, S.G., Loveland, T.R., Kurtz, R.M., 2004. Contemporary carbon dynamics in terrestrial ecosystems in the Southeastern Plains of the United States. Environ. Manag. 33, S442-S456.

Liu, S.G., Tan, Z.X., Li, Z.P., Zhao, S.Q., Yuan, W.P., 2011. Are soils of Iowa USA currently a carbon sink or source? Simulated changes in SOC stock from 1972 to 2007. Agric. Ecosyst. Environ. 140, 106-112.

Luo, Y.Q., Wu, L.H., Andrews, J.A., White, L., Matamala, R., Schafer, K.V.R., et al., 2001. Elevated $\mathrm{CO} 2$ differentiates ecosystem carbon processes: deconvolution analysis of Duke Forest FACE data. Ecol. Monogr. 71, 357-376.

Madsen, H., 2003. Parameter estimation in distributed hydrological catchment modelling using automatic calibration with multiple objectives. Adv. Water Resour. 26, 205-216.

Marta-Almeida, M., Reboreda, R., Rocha, C., Dubert, J., Nolasco, R., Cordeiro, N., et al., 2012. Towards operational modeling and forecasting of the Iberian shelves ecosystem. PLoS ONE 7 .

Mazzotti, F.J., Vinci, J.J., 2010. In Institute of Food and Agricultural Sciences (IFAS) Extension. Wildlife Ecology and Conservation Department. Institute of Food and Agricultural Sciences, University of Florida, Florida Cooperative Extension Service.

Moriasi, D.N., Arnold, J.G., Van Liew, M.W., Bingner, R.L., Harmel, R.D., Weith, T.L., 2007. Model evaluation guidelines for systematic quantification of accuracy in watershed simulations. Trans. ASABE 50, 885-900.

Neitsch, S.L., Arnold, J.G., Kiniry, J.R., Williams, J.R., King, K.W., 2005. Soil and Water Assessment Tool Theoretical Documentation. Grassland, Soil and Research Service, Temple, TX

Omernik, J.M., 1987. Ecoregions of the conterminous United States. Ann. Assoc. Am. Geogr. 77, 118-125.

Parton, W.J., Ojima, D.S., Schimel, D.S., 1994. Environmental-change in grasslandsassessment using models. Clim. Chang. 28, 111-141.

Parton, W.J., Schimel, D.S., Cole, C.V., Ojima, D.S., 1987. Analysis of factors controlling soil organic-matter levels in great-plains grasslands. Soil Sci. Soc. Am. J. 51, 1173-1179.

Pereira, A., Duarte, P., Reis, L.P., 2008. Agent-based Ecological Model Calibration-on the Edge of a New Approach, International Conference on Knowledge Engineering and Decision Support. 107-113 (Porto, Portugal).

PEST, 2003. Model-Independent Parameter Estimation, User's Guide for the PEST Software. Watermark Numerical Computing.

PRISM Climate Group, 2012. Parameter-elevation Regressions on Independent Slopes Model (PRISM) data: PRISM Climate Group Dataset. http://www.prism.oregonstate. edu/ (Accessed October 23, 2012).

R Development Core Team, 2009. R: A Language and Environment for Statistical Computing. R Foundation for Statistical Computing, Vienna, Australia.

Ricciuto, D.M. Davis, K.J., Keller, K., 2008. A Bayesian calibration of a simple carbon cycle model: the role of observations in estimating and reducing uncertainty. Glob. Biogeochem. Cycles 22.

Rykiel, E.J., 1996. Testing ecological models: the meaning of validation. Ecol. Model. 90, 229-244.

Schmidt, G., Liu, S., Oeding, J., Schmidt, G., Liu, S., Oeding, J., 2011. Derived Crop Management Data for the LandCarbon Project: U.S. Geological Survey Open-File Report 2011-1303. 15 (http://pubs.er.usgs.gov/publication/ofr20111303. Accessed October 20, 2012)

Soetaert, K., Petzoldt, T., 2010. Inverse modelling, sensitivity and Monte Carlo analysis in R using package FME. J. Stat. Softw. 33, 1-28.

Sohl, T., Sayler, K., 2008. Using the FORE-SCE model to project land-cover change in the southeastern United States. Ecol. Model. 219, 49-65.

Sohl, T.L., Sayler, K.L., Drummond, M.A., Loveland, T.R., 2007. The FORE-SCE model: a practical approach for projecting land use change using scenario-based modeling. J. Land Use Sci. 2, 1-24.

Tan, Z., Tieszen, L.L., Tachie-Obeng, E., Liu, S., Dieye, A.M., 2009. Historical and simulated ecosystem carbon dynamics in Ghana: land use, management, and climate. Biogeosciences $6,45-58$

Tan, Z.X., Liu, S.G., Johnston, C.A., Loveland, T.R., Tieszen, L.L., Liu, J.X., et al., 2005. Soil organic carbon dynamics as related to land use history in the northwestern Great Plains. Glob. Biogeochem. Cycles 19.

Tan, Z.X., Tieszen, L.L., Liu, S.G., Tachie-Obeng, E., 2010. Modeling to evaluate the response of savanna-derived cropland to warming-drying stress and nitrogen fertilizers. Clim. Chang. 100, 703-715.

Thyer, M., Leonard, M., Kavetski, D., Need, S., Renard, B., 2011. The open source RFortran library for accessing R from Fortran, with applications in environmental modelling. Environ. Model Softw. 26, 219-234

USDA-NRCS, 2009. Soil Survey Geographic (SSURGO) Database: U.S. Department of Agriculture, Natural Resources Conservations Service. (pp) http://soildatamart.nrcs. usda.gov (Accessed August 24, 2012).

USDA, 1993. CENTURY Soil Organic Matter Model Environment. Technical Documentation.

USGS, 2012. National Elevation Dataset: U.S. Geological Survey database. http://ned.usgs. gov/ (Accessed August 5, 2012).

van Griensven, A., 2006. Sensitivity, Auto-Calibration, Uncertainty and Model Evaluation in SWAT2005. 48 (Available online at http://biomath.ugent.be/ ann/swat_manuals/ SWAT2005_manual_sens_cal_unc.pdf (Accessed March 6, 2012.)).

van Griensven, A., Meixner, T., Grunwald, S., Bishop, T., Diluzio, A., Srinivasan, R., 2006. A global sensitivity analysis tool for the parameters of multi-variable catchment models. J. Hydrol. 324, 10-23.

Van Oijen, M., Rougier, J., Smith, R., 2005. Bayesian calibration of process-based forest models: bridging the gap between models and data. Tree Physiol. 25, 915-927.

Vrugt, J.A., Gupta, H.V., Bouten, W., Sorooshian, S., 2003. A shuffled complex evolution metropolis algorithm for optimization and uncertainty assessment of hydrologic model parameters. Water Resour. Res. 39. 
Wiken, E., Nava, F.J., Griffith, G., 2011. North American Terrestrial Ecoregions-Level III. In: McGinley, M. (Ed.), Commission for Environmental Cooperation, Montreal, Canada, p. 149.

Wu, Y., Liu, S., 2012a. Automating calibration, sensitivity and uncertainty analysis of complex models using the R package Flexible Modeling Environment (FME): SWAT as an example. Environ. Model Softw. 31, 99-109.

Wu, Y., Liu, S., 2012b. R-SWAT-FME User's Guide. U.S. Geological Survey, Reston, Virginia 5.

Wu, Y., Liu, S., 2014. Improvement of the R-SWAT-FME framework to support multiple variables and multi-objective functions. Sci. Total Environ. 466-467, 455-466.

Yuan, W., Liang, S., Liu, S., Weng, E., Luo, Y., Hollinger, D., et al., 2012. Improving model parameter estimation using coupling relationships between vegetation production and ecosystem respiration. Ecol. Model. 240, 29-40.

Zhang, X.S., Srinivasan, R., Bosch, D., 2009a. Calibration and uncertainty analysis of the SWAT model using genetic algorithms and Bayesian model averaging. J. Hydrol. 374, 307-317.
Zhang, X.S., Srinivasan, R., Zhao, K.G., Van Liew, M., 2009b. Evaluation of global optimization algorithms for parameter calibration of a computationally intensive hydrologic model. Hydrol. Process. 23, 430-441.

Zhao, M.S., Heinsch, F.A., Nemani, R.R., Running, S.W., 2005. Improvements of the MODIS terrestrial gross and net primary production global data set. Remote Sens. Environ. $95,164-176$.

Zhao, S.Q., Liu, S.G., Li, Z.P., Sohl, T.L., 2010a. Federal land management, carbon sequestration, and climate change in the Southeastern US: a case study with Fort Benning. Environ. Sci. Technol. 44, 992-997.

Zhao, S.Q., Liu, S.G., Yin, R.S., Li, Z.P., Deng, Y.L., Tan, K., et al., 2010b. Quantifying terrestrial ecosystem carbon dynamics in the Jinsha Watershed, Upper Yangtze, China from 1975 to 2000. Environ. Manag. 45, 466-475.

Zhu, Z., 2011. Baseline and Projected Future Carbon Storage and Greenhouse-Gas Fluxes in the Great Plains Region of the United States. U.S. Geological Survey, Reston, Virginia 28 (Available online at http://pubs.usgs.gov/pp/1787/p1787.pdf). 